Tropical Journal of Pharmaceutical Research April 2020; 19 (4): 887-892

ISSN: $1596-5996$ (print); 1596-9827 (electronic)

(C) Pharmacotherapy Group, Faculty of Pharmacy, University of Benin, Benin City, 300001 Nigeria

Available online at http://www.tjpr.org

Original Research Article

http://dx.doi.org/10.4314/tjpr.v19i4.30

\title{
Nurses perception of pharmaceutical care practice: A qualitative approach
}

\author{
Zelal Kharaba ${ }^{1,2}$, Rozina Kousar ${ }^{3}$, Yassen Alfoteih ${ }^{4}$, Saira Azhar ${ }^{5 *}$, Shujaat Ali \\ Khan $^{6}$, Ghulam Murtaza ${ }^{7 *}$ \\ ${ }^{1}$ Department of Clinical Sciences, College of Pharmacy, Al Ain University, Abu Dhabi, United Arab Emirates, ${ }^{2}$ Honorary \\ Associate Lecturer, Faculty of Medical Sciences, Newcastle University, Newcastle Upon Tyne, United Kingdom, ${ }^{3}$ Department \\ of Pharmacy, Women Institute of Learning, Abbottabad, Pakistan, ${ }^{4}$ City University College of Ajman, Ajman, United Arab \\ Emirates, ${ }^{5}$ Department of Pharmacy, University of Sargodha, Sargodha, Pakistan, ${ }^{6}$ Department of Pharmacy, COMSATS \\ University Islamabad, Abbottabad Campus, ${ }^{7}$ Department of Pharmacy, COMSATS University Islamabad, Lahore Campus, \\ Pakistan
}

*For correspondence: Email: saira.azhar@uos.edu.pk, gmdogar356@gmail.com; Tel: +92-314-2082826

Sent for review: 19 October 2019

Revised accepted: 24 January 2020

\begin{abstract}
Purpose: To evaluate the perception of nurses regarding pharmaceutical care services in the healthcare system of Khyber Pakhtunkhwa (KPK) Province of Pakistan.

Methods: This qualitative study was implemented by conducting semi-structured interviews. For data collection, interviews (face-to-face) were conducted after developing an interview guide. The interviewees were 18 nurses and were interviewed at their nursing stations in hospitals. Interviews were continued until the data reached a saturation point. The respondents signed a written consent form before the start of the interview.

Results: From the thematic content analysis, five major themes were extracted as stated here: (a) incognizance of pharmaceutical care; (b) collaboration of nurses and pharmacists; (c) improper distribution system; (d) lack of provision of patient counseling; and (e) pharmacist's role in reducing prescribing errors.

Conclusion: Based to the findings, Pakistani nurses have poor knowledge of pharmaceutical care, thus highlighting the need for organizing pharmaceutical care awareness programs for nurses. On the other hand, nurses have a positive perception of pharmacists' roles in the healthcare system and want to work with them.
\end{abstract}

Keywords: Perception, Pharmaceutical care, Qualitative study, Nurse, Patient care

\begin{abstract}
This is an Open Access article that uses a fund-ing model which does not charge readers or their institutions for access and distributed under the terms of the Creative Commons Attribution License (http://creativecommons.org/licenses/by/4.0) and the Budapest Open Access Initiative (http://www.budapestopenaccessinitiative.org/read), which permit unrestricted use, distribution, and reproduction in any medium, provided the original work is properly credited.
\end{abstract}

Tropical Journal of Pharmaceutical Research is indexed by Science Citation Index (SciSearch), Scopus, International Pharmaceutical Abstract, Chemical Abstracts, Embase, Index Copernicus, EBSCO, African Index Medicus, JournalSeek, Journal Citation Reports/Science Edition, Directory of Open Access Journals (DOAJ), African Journal Online, Bioline International, Open-J-Gate and Pharmacy Abstracts

\section{INTRODUCTION}

Pharmacists, physicians, nurses, and other healthcare professionals are expected to make clinical decisions [1,2]. More specifically, pharmacists have an important role in delivering health services due to their knowledge and direct dealings with patients [3]. However, pharmaceutical care cannot be given without involving other healthcare professionals including physicians and nurses. Nurses are involved in delivering patient care in every area of 
healthcare. The presence of nurses at every level, and their knowledge allows them to an important role in patient safety. Additionally, they are responsible for accurate drug administration [4].

Due to their frequent interactions with patients, nurses can efficiently transfer health-related information from pharmacists to patients. They can also help pharmacists to optimize patients' drug therapy and also develop pharmaceutical care plans for individual patients [5]. Moreover, in developing countries such as Pakistan, healthcare facilities are poor and sparsely available due to the deficiency of qualified and trained staff, economic limitations, and limited availability of standard practice guidelines.

The perception of nurses in Pakistan has been previously assessed through studies conducted to evaluate the role of pharmacists in private sector hospitals in the city of Karachi in Pakistan [6] and public sector hospitals in the Punjab province, Pakistan [7] To the best of our knowledge, this is the first qualitative study conducted to evaluate the perception of nurses in KPK province. This study was conducted to obtain nurses' perceptions regarding the pharmaceutical care services in the healthcare system of KPK province, Pakistan.

\section{METHODS}

\section{Study design}

This was a qualitative study in which semistructured interviews were conducted for data collection. This type of interview was conducted to assess the respondents' knowledge, understanding, and perception regarding pharmaceutical care services in detail. In this context, a semi-structured interview technique is a useful approach when respondents are confused and feel reluctant to respond to formal questioning. For the conduction of semistructured interviews, an interview guide was developed after extensively reviewing the literature [6,8-10]. The interview guide served as a checklist that ensured that all the respondents were asked similar questions.

\section{Sample size and sampling technique}

The first participant was located through one of the researchers' personal contacts, and the remaining were contacted using the snowball sampling technique. The sample size was based on the saturation point of data. A total of 18 participants were interviewed. They belonged to various cities in KPK Province of Pakistan. The time and place of the interviews were arranged telephonically. The participants were interviewed at their work-places (nursing stations). Before starting the interview, written consent was obtained from each participant in the study. An ethical approval letter was obtained from the Departmental Research Ethical Committee.

\section{Interview implementation and data analysis}

Using open-ended questions, the participants were asked to share their points of view in the last part of the interview. For their convenience, the participants were interviewed at the nursing stations. Most of the interviews were completed in about $20-30 \mathrm{~min}$. These interviews were carried out in English by one of the authors (RK); the interviews were also audio-taped and later transcribed verbatim. To verify the accuracy of the transcripts, the audio-taped interviews were carefully assessed, and their contents of were thematically analyzed. Data saturation was achieved at the 18th interview since no new theme was obtained in the last two interviews.

\section{RESULTS}

\section{Respondent's characteristics}

From the interviewees, it was found that $88.8 \%$ $(n=16)$ were female, and $11.1 \%(n=2)$ were male. The majority of interviewees $(61.1 \% ; n=$ 11) were in-charge nurses, while $44.4 \%(n=8)$ of the nurses had less than 10 years of practical experience. The characteristics (demography, gender, current position, and experience) of the respondents are summarized in Table 1.

Table 1: Demographic profile of nurses

\begin{tabular}{lcc}
\hline Variable & $\begin{array}{c}\text { Frequency } \\
(\mathbf{N})\end{array}$ & $\begin{array}{c}\text { Percent } \\
(\%)\end{array}$ \\
\hline Age (years) & & \\
$20-30$ & 7 & 38.8 \\
$31-40$ & 7 & 38.8 \\
$41-50$ & 3 & 16.6 \\
$>50$ & 1 & 5.5 \\
Gender & & \\
Male & 2 & 11.1 \\
Female & 16 & 88.8 \\
Current position & & \\
Staff/In-charge nurse & 11 & 61.1 \\
Head nurse & 5 & 27.7 \\
Matron & 2 & 11.1 \\
Years of practice & & \\
1-10 & 8 & 44.4 \\
11-20 & 6 & 33.3 \\
21-30 & 4 & 22.2 \\
\hline
\end{tabular}

Five major themes were obtained (Table 2) as listed here: (a) Incognizance of pharmaceutical care; (b) collaboration of nurses and 
pharmacists; (c) Improper distribution system; (d) lack of provision of patient counseling; and (e) the pharmacist's role in reducing the prescribing errors.

\section{Theme 1: Incognizance of pharmaceutical care}

The majority of the nurses were unaware of the term pharmaceutical care, which showed their poor interaction with pharmacists. They mentioned that they had no idea about this term and were interested in knowing about it (Table 2).

\section{Theme 2: Collaboration of nurses and pharmacists}

The responses of the majority of the respondents revealed that there was a communication gap between the pharmacists and nurses (Table 2). It suggests that the working relationship between the pharmacists and nurses should be strengthened. The nurses also mentioned that pharmacists could reduce the nurses' workload and could counsel the patients more appropriately.

The participants further pointed out that patients' health conditions could be improved by collaborative work between pharmacists and nurses. Additionally, the participants suggested that pharmacists could improve the nurses' knowledge of drugs and help the nurses to be more confident in performing their duties.

\section{Theme 3: Improper distribution system}

The majority of the nurses reported a lack of proper drug distribution system and disclosed that the hospitals did not follow a proper system to ensure the availability of medicines at wards; this was particularly true of potent medicines (Table 2). They also pointed out that the hospital pharmacists asked them to visit the hospital pharmacy along with the patient's chart to collect the medicines at the time of administration. This is perhaps due to the unavailability of a sufficient number of pharmacists in the hospitals.

The participants further mentioned that due to a delay in the availability of medicines, it becomes difficult for them to administer the medicines in time. They also mentioned the reasons for the delayed availability of medicines as the absence of pharmacists and the insufficiency of nursing staff. In this context, one respondent suggested that a pharmacist must be appointed in each ward to resolve this issue.

\section{Theme 4: Lack of provision of patient counseling}

The majority of nurses were of the view that pharmacists were not actively involved in patient counseling (Table 2). According to some of the participants, pharmacists were focusing more on other activities like medicine dispensing and procurement. Moreover, an insufficient number of pharmacists hospitals was the cause of pharmacist's inability to counsel patients. Moreover, they also mentioned that pharmacists counsel hospital outpatients but not those admitted in hospital wards. A few of the nurses ascribed this to the unavailability of pharmacists at the ward level.

\section{Theme 5: Pharmacists reduce prescribing errors}

Nurses have a positive perception of the pharmacists' involvement in direct patient care (Table 2). According to the majority of the nurses, pharmacists' involvement would help reduce prescription and medication errors; for instance, the rationalized prescription of antibiotics.

\section{DISCUSSION}

Nursing is a very important yet demanding profession. This study focuses on the nurses' perception of pharmaceutical care services in the healthcare system of KPK, Pakistan. Results derived from this study will be relevant for planning, developing and implementing a practical action plan to improve the healthcare system worldwide. Through the concept of systematic feedback and action plan of hospital management, work can be remodeled or redesigned to suit human features and capabilities. Moreover, nurses are responsible for the accurate administration of medicines to patients [10]. However, the majority of the nurses were unaware of the term "pharmaceutical care". The reasons may be that the pharmacists were not provided with the opportunity to interact with other healthcare professionals, which ultimately led to poor awareness among nurses about pharmacists' role in patient care. These findings are consistent with a previous study conducted in Pakistan, where the nurses had negative perceptions regarding pharmacists [6]. Additionally, in another study conducted in Dubai, nurses expressed their acceptance of pharmacists' roles as healthcare professionals. According to them, a pharmacist is the right person from whom can seek the provision of updated drug information [1]. 
Table 2: Themes and nurses' responses

\begin{tabular}{|c|c|c|c|}
\hline No. & Theme & $\begin{array}{c}\text { Nurse } \\
\text { no. }\end{array}$ & Nurse's response \\
\hline \multirow[t]{2}{*}{1} & \multirow{2}{*}{$\begin{array}{l}\text { Incognizance of } \\
\text { pharmaceutical } \\
\text { care }\end{array}$} & N1 & $\begin{array}{l}\text { No, I have no idea about pharmaceutical care. Can you please tell me } \\
\text { what pharmaceutical care is? }\end{array}$ \\
\hline & & N2 & $\begin{array}{l}\text { No, I do not know. It is the first time I have heard this word. We are using the word } \\
\text { nursing care, but what is pharmaceutical care? }\end{array}$ \\
\hline \multirow[t]{3}{*}{2} & \multirow{3}{*}{$\begin{array}{l}\text { Collaboration of } \\
\text { nurses and } \\
\text { pharmacists }\end{array}$} & N1 & $\begin{array}{l}\text { Pharmacists can reduce our workload in providing healthcare services to patients. } \\
\text { They can counsel the patients in a better way about drug use and doses. }\end{array}$ \\
\hline & & N7 & $\begin{array}{l}\text { Collaborative work of pharmacists and nurses can improve the patient's health } \\
\text { conditions. They have a broad vision about drugs, once they will guide the } \\
\text { patient; the patient will use drugs accordingly and will be improved. }\end{array}$ \\
\hline & & N10 & $\begin{array}{l}\text { Pharmacists can improve our knowledge regarding drug uses, interactions and } \\
\text { side effects due to which we will be more confident in the provision of advice and } \\
\text { drug information to the discharged patients. }\end{array}$ \\
\hline \multirow[t]{3}{*}{3} & \multirow{3}{*}{$\begin{array}{l}\text { Improper } \\
\text { distribution } \\
\text { system }\end{array}$} & N2 & $\begin{array}{l}\text { Pharmacists say to come to hospital pharmacy along patients' charts and collect } \\
\text { the costly or potent medicines at the time of administration to the patient. }\end{array}$ \\
\hline & & N3 & $\begin{array}{l}\text { Sometimes, we are unable to administer the medicines to the patients at the } \\
\text { proper time, because of the imperfect distribution system, unavailability of } \\
\text { pharmacists in the wards and shortage of nursing staff, }\end{array}$ \\
\hline & & N4 & $\begin{array}{l}\text { Due to a lack of proper distribution system, we sometimes have to visit the } \\
\text { hospital pharmacy three to four times a day, which is very problematic for us and } \\
\text { time-consuming. I think this problem can be solved by placing a pharmacist in } \\
\text { each ward. }\end{array}$ \\
\hline \multirow[t]{3}{*}{4} & \multirow{3}{*}{$\begin{array}{l}\text { Lack of } \\
\text { provision of } \\
\text { patient } \\
\text { counseling }\end{array}$} & N2 & $\begin{array}{l}\text { Pharmacists are not involved in-patient counseling. They are involved in drug } \\
\text { dispensing and drug procurement activities. Nurses are also not involved in } \\
\text { counseling; Nurses administer the prescribed medicines to all the patients on time }\end{array}$ \\
\hline & & N9 & $\begin{array}{l}\text { Pharmacists do not have enough time for the provision of drug information to } \\
\text { patients. They have a heavy workload. Moreover, the number of pharmacists is } \\
\text { low when compared to the number of patients to be counseled }\end{array}$ \\
\hline & & N13 & $\begin{array}{l}\text { Pharmacists are limited to the hospital pharmacy. They provide information to the } \\
\text { outpatients but are not involved in counseling of hospital inpatients due to their } \\
\text { unavailability in the hospital wards }\end{array}$ \\
\hline \multirow[t]{3}{*}{5} & \multirow{3}{*}{$\begin{array}{l}\text { Pharmacists } \\
\text { reduce } \\
\text { prescribing } \\
\text { errors }\end{array}$} & N1 & $\begin{array}{l}\text { Pharmacist's involvement in ward rounds can reduce prescribing errors because } \\
\text { of their detailed knowledge regarding drugs. They can reduce the illegal practice } \\
\text { of prescribing drugs for no symptoms. }\end{array}$ \\
\hline & & N3 & $\begin{array}{l}\text { Prescribing errors like drug-drug interactions and drug-disease interactions can } \\
\text { be prevented by pharmacists. For instance, patients are sometimes prescribed } \\
\text { with medicines that have severe interactions or sometimes medicines do not need } \\
\text { to be prescribed. }\end{array}$ \\
\hline & & N5 & $\begin{array}{l}\text { Pharmacists have more knowledge of drugs, so they can play an important role in } \\
\text { the reduction of prescribing errors, especially in case of antibiotics, where two or } \\
\text { three antibiotics are prescribed at a time, so the pharmacist can choose the best } \\
\text { antibiotic for the patient in such cases. }\end{array}$ \\
\hline
\end{tabular}

Various reasons that contribute to the nurses' unawareness could be highlighted that include but are not limited to the following: the lack of pharmaceutical care programs for healthcare professionals as well as the lack of active participation of pharmacists in such programs. These findings are in line with another study [8], where many of the respondents had not participated in pharmaceutical care programs that are important in terms of promoting rational drug use. Additionally, medication errors can be reduced by organizing pharmaceutical care programs for nurses, physicians, pharmacists and patients [11].

Moreover, from this study, it can be inferred that the nurses have a positive perception regarding collaboration with pharmacists. They considered the pharmacists as reliable sources of drug information. These findings are in accordance with those of a study conducted in Sweden [12], where the nurses were agreed to collaborate with pharmacists. According to them, pharmacists could help improve patients' health outcomes.

Meanwhile, nurses play an important role in direct patient care since they have the responsibility to administer the medicines at the right time to the right patient [8]. Thus, medication dispensing errors can be reduced by inter-professional collaboration among nurses, pharmacists, and other health professionals. This is consistent with the findings of another study [11] where collaborative work reduced prescribing and dispensing errors.

Overall, in this study, the majority of the nurses were of the view that pharmacists will help them 
in improving their knowledge and reduce their workload by involvement in patient care. This finding is in contrast to a previous study [13], where the nurses had a negative perception regarding pharmacists' roles. According to them, pharmacists 'involvement would reduce their worth and cause interruptions in their work.

Further, the findings of this study further revealed the lack of appropriate and systematic approaches for the distribution of the drugs in the hospitals. The majority of nurses stated that improper distribution is one of the major constraints in the on-time administration of drugs. They were of the view that it may be due to the deficiency of pharmacists and their unavailability around the clock. Moreover, some nurses emphasized the need for and availability of pharmacists in the wards. They thought that the availability of pharmacists in the wards would help them in consultations and reduce their workload. These findings are in line with another qualitative study [13] where the nurses agreed on the insufficiency of pharmacy staff and emphasized that the number of pharmacists should be made adequate.

In addition, the majority of the nurses in this study stated that pharmacists were not actively involved in patients' counseling activities and direct patients' care; instead, they were more engaged in drug procurement and drug dispensing activities. This is similar to a previous study [7] where the nurses reported the lack of pharmacists' participation in patient counseling activities.

Moreover, when the nurses were asked to mention the reasons for their negative perception regarding counseling, many of them pointed to the lack of availability of a sufficient number of pharmacists in the hospitals. According to them, pharmacists provided counseling to out-patients but not to hospitals in-patients due to an inadequate number of pharmacists in the hospital. These findings are consistent with a previous study, in which the participants reported an increased workload due to the insufficient number of pharmacists [10].

However, the nurses who participated in this study agreed that drug prescription issues can be solved by the presence of a pharmacist in the wards. They also accepted the role of pharmacists as drug experts and believed that prescribing errors can be reduced by pharmacists' involvement in ward rounds. These findings are supported by a Nigerian study, in which emphasis was placed on the recruitment of more pharmacists in hospitals since their involvement had proved helpful in reducing prescribing errors [10]. Further, another study conducted in United Kingdom also reported the reduction in prescribing errors due to increased pharmacists' involvement in ward rounds [9].

Additionally, It has been postulated that pharmacists significantly helped identify, resolve, and prevent drug-related problems [14]. Further, pharmacists' presence in the wards has resulted in improved patient-pharmacists communication, reduced prescribing errors, and improved health outcomes [15]. Therefore, ward rounds are important for ensuring the quality of pharmaceutical care. Moreover, during ward rounds, healthcare professionals can work together to promote the safe and effective administration of medicines, the rational use of medicines, and adverse drug reactions monitoring as well as enhance patients' education [16].

\section{Limitation of the study}

This study involved the nurses working in various regions of KPK Province of Pakistan. Thus, the findings of this study may not be applicable to the whole country, although it is possible that nurses in other provinces of Pakistan may have similar perceptions regarding the pharmaceutical care services provided to patients in the healthcare system.

\section{CONCLUSION}

The findings of the present study revealed that nurses in Pakistan are not sufficiently aware of the term, "pharmaceutical care" and hence, pharmaceutical care awareness programs should be organized for patients as well as healthcare professionals. However, nurses have a positive perception of pharmacists and are willing to collaborate with them. Further, pharmacists' pharmaceutical care role will help to reduce nurses' workload as well as help them improve their knowledge of drugs and patient care.

\section{DECLARATIONS}

\section{Conflict of interest}

No conflict of interest is associated with this work.

\section{Contribution of authors}

We declare that this work was done by the authors named in this article and all liabilities 
pertaining to claims relating to the content of this article will be borne by the authors.

\section{Open Access}

This is an Open Access article that uses a funding model which does not charge readers or their institutions for access and distributed under the terms of the Creative Commons Attribution License (http://creativecommons.org/licenses/by/ 4.0) and the Budapest Open Access Initiative (http://www.budapestopenaccessinitiative.org/rea d), which permit unrestricted use, distribution, and reproduction in any medium, provided the original work is properly credited.

\section{REFERENCES}

1. Rayes IK, Hassali MA, Abduelkarem AR. Nurses' Perception and Expectations towards the Role of Community Pharmacists in Dubai's Healthcare System: a Qualitative Approach. Curr Nursing J 2015; 2(1): 1418.

2. Hepler CD, Strand LM. Opportunities and responsibilities in pharmaceutical care. Am J Hospital Pharm 1990; 47(3): 533-543.

3. Strand LM, Cipolle RJ, Morley PC, Frakes MJ. The impact of pharmaceutical care practice on the practitioner and the patient in the ambulatory practice setting: twenty-five years of experience. Curr Pharm J 2004; 10 (31): 3987-4001.

4. Smith F. Private local pharmacies in low-and-middle income countries: a review of interventions to enhance their role in public health. Trop Med Int Health 2009; 14(3): 362-372.

5. Fletcher J, Hogg W, Farrell B, Woodend K, Dahrouge S, Lemelin J, Dalziel W. Effect of nurse practitioner and pharmacist counseling on inappropriate medication use in family practice. Canadian Family Physician 2012; 58(8): 862-868.

6. Khan AN, Khan MU, Shoaib MH, Yousuf RI, Mir SA. Practice Nurses and Pharmacists: A Perspective on the
Expectation and Experience of Nurses for Future Collaboration. Oman Med J 2014; 29(4): 271-275.

7. Azhar S, Hassali MA, Ibrahim MIM, Saleem F, Yen LS. A survey evaluating nurses' perception and expectations towards the role of pharmacist in Pakistan's healthcare system. J Advanced Nursing 2012; 68(1): 199-205.

8. Varela NMD, Oliveira DRD, Argilagos CS, Castro $K$, Perez EM, Clavel YH, Bisset NS. What is the role of the pharmacist? Physicians' and nurses' perspectives in community and hospital settings of Santiago de Cuba. Brazil J Pharm Sci 2011; 47(4): 709-718.

9. Franklin A, Panyin AB, Vincent $B$, Isaac $K$, Stephen $C$. Medication Safety Activities of Hospital Pharmacists in Ghana; Experiences and Expectations of Doctors and Nurses. Int J Pharm Pharm Sci 2014; 6(10): 525-529.

10. Demehin Al, Babalola OO, Erhun WO. Pharmacists and Nurses Perception of Medication Errors in a Nigerian University Teaching Hospital. Int J Health Res 2008; 1(2): 51-61.

11. Bakr MM, Atalla HR. Medication errors, causes and reporting behaviors as perceived by nurses. J Pharm Biomed Sci 2012; 19(17): 1-7.

12. Gillespie $U$, Morlin $C$, Udenaes HM, Hedstrom $M$. Perceived value of ward-based pharmacists from the perspective of physicians and nurses. Int J Clin Pharm 2012; 34(1): 127-135.

13. Azhar S, Hassali MA, Izham MI, Khan TM. A Qualitative Evaluation of Nurses' Perception towards the Role of Pharmacist in Healthcare Setup in Pakistan. Health Med 201; 4(1): 71-76.

14. Dahal $P$, Venkataraman $R$, Fuloria PC. Assessment of clinical pharmacist intervention in tertiary care teaching hospital of southern India. Asian $\mathrm{J}$ Pharm Clin Res 2013; 6(2): 258-261.

15. Sello DA, Dambisya YM. Views of pharmacists on involvement in ward rounds in selected public hospitals in Limpopo Province. J Interdisciplin Health Sci 2014; 19(1): 740-746.

16. Reeves S, Lewin S. Interprofessional collaboration in the hospital: strategies and meanings. J Health Services Res Policy 2004; 9(4): 218-225. 